\title{
The Content Validity on Reading Comprehensions of National Ver- sions of National Matriculation English Test in 2020 - Based on Bachman and Palmer Test Task Characteristics Theory
}

Miao Li*

China West Normal University, Nanchong 637000, Sichuan Province, China. Email:1661979011@qq.com

Abstract: Bachman and Palmer constructed a framework based on their test task characteristics theory, and designed five parts in the framework, which furnished the validity testing research with theoretical support. Based on their framework, this paper's research objects are the national versions of National Matriculation English Test (NMET) in 2020, as well as it tests the content validity of expected answers and text input of reading comprehension in the national versions I, II, and III. The results show that the overall quality of reading comprehension of these three papers is high, which meets the requirements of the curriculum standards and examination syllabus. However, there are shortcomings in the length, difficulty, text types and reading skills evaluation. Therefore, the article length distribution should be more reasonable, the article difficulty should be more moderate, the text types should be more diversified, and the assessment of reading skills should be more comprehensive and balanced in the future, so as to further improve and perfect the content validity of the reading comprehension of NMET.

Keywords: NMET; National Versions; Reading Comprehension; Content Validity

\section{Introduction}

The largest test in China is the national college entrance examination, because it is a high-stake and high-risk selection test, it has a profound significance on the society. The national college entrance examination is regarded as the test which has the largest backwash effect in China. It has a strong influence on all aspects of basic education. Therefore, the analysis of the validity of the contents of NMET can not only further improve the test, but also provide feedback to teaching, thereby promoting learning by testing. Standards for Educational and Psychological Testing defines the validity as "the degree to which evidence and theory support the interpretation of $\operatorname{scores}^{\text {"[1] }}$. It is, put simply, the extent to which the test has achieved expectations and purposes. Validity is an important and core indicator in language test. Also pointed out that since it is validity that provides evidences for test scores' interpretation and usage, it should be the most significant aspect in a test. The validity is divided into three aspects, namely, internal validity, external validity and structural validity, and among these three, content validity is considered to be the most vital validity in the internal validity. And the well-publicized definition of content validity is that "the adequacy of selected content samples or the representativeness of the contents of a measurement tool (including materials, subjects, and topics)" ${ }^{[2]}$.which means that the selected materials and the tested skills must be representative, and the two should be within the specified range.

In 2020, there are 31 provinces (including autonomous regions and municipalities) in China that has adopted the national version of NMET under the guidance of new curriculum standard. Among them, different provinces and re-

Copyright (C) $2021 \mathrm{Miao} \mathrm{Li}$

doi: $10.18686 / \mathrm{mmf} . v 5$ i1.3305

This is an open-access article distributed under the terms of the Creative Commons Attribution Non-Commercial License

(http://creativecommons.org/licenses/by-nc/4.0/), which permits unrestricted non-commercial use, distribution, and reproduction in any medium,

provided the original work is properly cited. 
plied to 9 provinces including Fujian, Anhui, Hubei and Shanxi; National Version II (NV II) is mainly applicable to 10 provinces including Liaoning, Jilin, Heilongjiang and Chongqing; National Version III (NV III) is mainly applied to five provinces including Yunnan, Guizhou area and some border areas such as Tibet. Reading is a very important language skill that students must master. It builds a bridge for them to broaden their horizons and to learn about foreign cultures. What's more, one of the main purposes in language testing is to test test-takers' reading skills, and also it accounts for a high proportion in the NMET. Thus, it is necessary for us to test the content validity of it. In the existing researches, some scholars have conducted diachronic research on the reading part of the national versions or specific provinces and cities. ${ }^{[3]}$ and other scholars have finished researches on the grammar filling and writing parts in the national versions ${ }^{[4]}$. In general, scholars have done less research on the national versions of NMET in 2020, especially for the reading comprehension. Therefore, this article will focus on testing the content validity of the reading comprehension based on the existing researches, taking the national versions of NMET in 2020 as the research objects, and comparing the reading comprehension of the national versions I, II, and III.

\section{Theoretical Framework and Research Basis}

\subsection{Theoretical Framework}

In the late 1990s, Bachman and Palmer (1999) built a theoretical framework based on the test task characteristics, which includes five parts: test environment, test instructions, text input, expected answers, the relationship between the last two ${ }^{[5]}$. Bachman and Palmer's framework offers theoretical supports for the researches on testing the content validity. For this paper, it formulated the analysis framework of reading comprehension of national versions of NMET in 2020 based on the Bachman and Palmer's framework, and in the light of relevant requirements. Among them, the expected answers and text input are the focus of Bachman and Palmer when constructing the content of this framework. For the expected answers, the reaction displayed by test-takers when dealing with questions and the output when answering the test questions are all expected answers, and the text input refers to the materials that test-takes' need to handle and answer, which include the presented forms and language features. In view of the fact that this study is only an analysis of the three sets of national versions of NMET in 2020, for each set of examination papers only has 4 reading materials, and since the small number will limit the richness of the materials, therefore the text input of this study is only from three aspects to do the analysis: the article length, the article difficulty and text types.

Table 1. Analysis Framework of reading comprehension of NMET in 2020

\begin{tabular}{|l|l|l|}
\hline & Items & Description \\
\hline \multirow{3}{*}{ Text input } & article length & single article length, total article length \\
\cline { 2 - 3 } & article difficulty & readability \\
\cline { 2 - 3 } Expected an- & text types & reading skills \\
swers & $\begin{array}{l}\text { understand the main idea, grasp the specific information in the text, infer the } \\
\text { meaning of words and phrases from the context, make judgments and inferences, } \\
\text { understand the basic structure of the article, understand the author's intentions, } \\
\text { opinions and attitudes }\end{array}$ \\
\hline
\end{tabular}

\subsection{Research basis and objects}

In January 2018, Chinese Ministry of Education promulgated the New Curriculum Standard (NCS). It has caused profound influence on the national college entrance examination. And because of it, the national versions were also called the national versions of new curriculum standard. Therefore, it is very necessary to test the NMT based on the NCS. Subsequently, Chinese State Council issued a statement stating that relevant provinces and regions in the country should make changes in the ways of educating people in high schools. Thus, the relevant areas and schools need to omit the examination syllabus, speed up the reform process, and change the traditional education styles to comprehensively perfect the ways of educating people in high schools in the new era. In this regard, this article takes the first section of 
reading comprehension of the national versions I, II, and III of NMET in 2020 which based on the new curriculum standard as the research objects, and focuses on the content validity analysis of the reading comprehension. In the first section of each version, there are four reading materials, represented by A-D, so there are 12 texts in all three sets of test papers, and 45 test questions in total.

\section{Research Results and Discussion}

\subsection{Text Input}

This paper will analyze and discuss the text input characteristics of the reading comprehension of the three sets of NMET in 2020 from three aspects: article length, article difficulty, and text types.

\subsubsection{Article length}

According to the examination syllabus published by Chinese State Council, it brings forward clear requirements for the reading comprehension of the national versions of NMET. About the article length, it suggests that the total words of four reading materials in the first section should be more than 900 words. As shown in Table 2 below, the total lengths of the four reading comprehension materials in National Versions I, II, and III are respectively 1162, 1204, and 1119 , which all exceed the requirement of at least 900 words in the syllabus. In the test, we have to consider not only the total length of the reading materials, but also the length of each piece of materials. According the syllabus, the words of each reading material should not be less than 200, and try not to exceed 500 words. From table 2, we can see that the length of each reading material meets the above numerical range, and the average length is also around 300 words. Among them, the NV II has the longest average length, and the NV III is the shortest. For the length of a single reading material, the article A in NV II and NV III are not the shortest articles in each four reading materials. It would be better that the article length arranges from short to long and from easy to difficult, which will help to reduce the pressure on test-takers. Therefore, the length of the article in the national versions can be further adjusted to make its distribution more balanced to help prompt their performance.

Table 2. The length of the reading materials of NMET in 2020

\begin{tabular}{|l|c|c|c|c|c|c|}
\hline & A & B & C & D & Total length & Average length \\
\hline NV I & 221 & 297 & 311 & 333 & 1162 & 291 \\
\hline NV II & 283 & 246 & 331 & 344 & 1204 & 301 \\
\hline NV III & 247 & 248 & 320 & 304 & 1119 & 280 \\
\hline
\end{tabular}

\subsubsection{Article Difficulty}

It is widely believed that the readability of the article consists of comprehension of the reading materials and the difficulty to read. When selecting the reading materials for the English test paper, the readability of the article needs to be considered, and test-designers should control the difficulty of the materials, and strive to test the test-takers' actual reading abilities in the maximal degree. Nowadays, the Flesh readability index has become the most authoritative reference in the academic field when conducting readability researches. There are seven levels in the Flesh readability index, the readability index is between $0-100$. The indexes are related to the degree of difficulty. The high index means that it is easy to read, and the low index means that the article is difficult.

Table 3. Reference table for Flesh readability index

\begin{tabular}{|l|l|l|l|l|l|l|l|}
\hline Description & very hard & hard & a little hard & standard & a little easy & easy & very easy \\
\hline Readability index & $0-30$ & $30-50$ & $50-60$ & $60-70$ & $70-80$ & $80-90$ & $90-100$ \\
\hline
\end{tabular}

This paper also uses Flesh's readability to analyze the three sets of national versions of NMET in 2020. In general, the readability indexes of the 3 sets of test papers are approximately between 50-60, which is in the range of "slightly hard". The national college entrance examination is a selective examination, so it is reasonable for the readability value 
in this range. In all these three national versions, the NV I has the highest average readability index, while the lowest is the NV II. Among the 12 reading comprehensions, most of the articles are close to or in the "a little hard" range, so the difficulty of reading comprehensions of all three national versions is appropriate. It can be seen from Table 4 that the article A in the NV II is in the "very hard" range, with a readability index of 19.5. This level is equivalent to the college students' reading levels in English-speaking countries. Thus, it may be a bit hard for Chinese students who take the NMET. Therefore, the subsequent formulation of the proposition should consider reducing the difficulty. Secondly, among the 12 reading materials in 3 sets of examination papers, the readability indexes of the article B in the NV I and the article D in the NV II are between 70-80, which belongs to the "a little easy" range. For selective examinations, reading materials of this range may be somewhat easy, and it should be considered increasing the difficulty appropriately. In summary, the overall Flesh readability of the NV III is more reasonable compared with other two national versions, which can better test the actual reading abilities of test-takers. In contrast, the physical readability indexes of the reading comprehension of other two sets of national papers are relatively unreasonable, and need to be adjusted as soon as possible.

Table 4. The Flesh readability indexes of reading materials of NMET in 2020

\begin{tabular}{|l|c|c|c|c|c|c|}
\hline \multirow{2}{*}{} & \multicolumn{6}{|c|}{ Flesh readability } \\
\cline { 2 - 7 } & A & B & C & D & Averages & Description \\
\hline NV I & 51.2 & 72.2 & 59.3 & 58.6 & 60.325 & Standard \\
\hline NV II & 19.5 & 46.0 & 56.9 & 73.9 & 49.075 & Hard \\
\hline NV III & 50.6 & 60.3 & 54.5 & 49.0 & 53.6 & A little hard \\
\hline
\end{tabular}

\subsubsection{Article Types}

According to the relevant regulations in the NCS, the modal forms and stylistic expressions of a text are the criteria for distinguishing its types. Among them, the stylistic expression forms of a text are mainly narrative essays, expository essays, argumentative essays and practical essays. Oral and written forms are the two main modal forms of a text . What's more, clear requirements for the text content have been given in the examination syllabus, that is, the text content needs to be easy for test-takers to understand and read. Therefore, this research mainly conducts analysis from four aspects of text types: narrative essay, argumentative essay, explanatory essay, and practical essay. From the table 5, we can see that the four text types are all covered in the NVs I and II, but the argumentative essay is absent in the NV III. Based on this, it is suggested that more consideration should be given to the diversification of text types in future propositions.

Table 5. The text types of reading materials of NMET in 2020

\begin{tabular}{|l|c|c|c|c|}
\hline & Narrative essay & Argumentative essay & Explanatory essay & Practical essay \\
\hline NV I & 1 & 1 & 1 & 1 \\
\hline NV II & 1 & 1 & 1 & 1 \\
\hline NV III & 1 & 0 & 2 & 1 \\
\hline
\end{tabular}

\subsection{Expected Answers}

According to the main contents of the expected answers and under the clear requirements of the examination syllabus, test-takers not only need to know the basic structure, content, and main points of the article, but also need to understand the author's views, attitudes and intentions. To make it easier to collect statistics, the 6 skills are respectively counted as skill 1, skill 2, skill 3, skill 4, skill 5, and skill 6. It can be seen from the table that in the three sets of NMET, assessment of skill 2 accounts for $66.67 \%$ of the total skills assessments, which is the core of the 3 sets of papers. But skill 3 is not involved in all three sets of papers. In terms of the frequency of assessing each skill, most skills are assessed only once in the NV I, apart from skill 2 and skill 5. In the NVs II and III, some skills were assessed twice, but 
neither of them assessed the skill of understanding the author's intentions, attitudes, and opinions. Generally speaking, the examination of reading skills in the three sets of test papers is relatively comprehensive, but not balanced. Therefore, the assessment of teat-takes' reading skills should be more comprehensive and balanced in the future propositions.

Table 6. Expected answers of reading comprehension of NMET in 2020

\begin{tabular}{|l|c|c|c|c|c|c|}
\hline & Skill 1 & Skill 2 & Skill 3 & Skill 4 & Skill 5 & Skill 6 \\
\hline NV I & 1 & 11 & 1 & 1 & 0 & 1 \\
\hline NV II & 2 & 10 & 2 & 1 & 0 & 0 \\
\hline NV III & 2 & 10 & 1 & 2 & 0 & 0 \\
\hline
\end{tabular}

\section{Conclusion and Suggestions}

By analyzing the content validity of reading comprehension of national versions of NMET in 2020, we can find that the overall quality of these three sets of test papers is relatively high. The total number of words in reading materials is all more than 900 words, which meets the requirements of the examination syllabus. The overall readability of the 12 articles is appropriate, which can better test the test-takers' actual reading abilities. The text types are diversified, involving narrative essays, argumentative essays, explanatory essays and practical essays. The expected answers are also comprehensive. However, the three sets of papers also have their own shortcomings. The readability index of the NV II is relatively low, and the readability index of article A in NV II is too low, and the article A is located in the first of all four reading materials, so if it is too hard, it may influence test-takers' performance. In terms of text types, the argumentative essay in NV III is absent, so it is relatively lacking in diversity. And in terms of reading skills, the NV I mainly assesses the understanding of specific information topics in the text. The NVs II and III do not assess the author's intentions, opinions and attitudes, and none of the three sets of papers assesses the basic structure of articles. In the future proposition, the three sets of paper should learn from each other, so as to make the distribution of the article length more reasonable, the difficulty of the article more appropriate, the text types more diversified, and the assessment of reading skills more comprehensive and balanced, in order to improve and perfect the validity of reading comprehension.

The theoretical framework of this paper is based on Bachman and Palmer's theoretical framework of test task characteristics. And for this reason, this paper only analyzes the content validity of reading comprehension of national versions in NMET from two aspects: text input and expected answer. Future research can be carried out from the perspective of the proposition techniques, for example, the selection and adaptation of reading materials, or how to set questions for reading comprehension and how to make interference items.

\section{References}

1. AERA, APA, NCME. Standards for Educational and Psychological Testing. Washington, DC: AERA; 2014.

2. Kerlinger FN. Foundations of Behavior Research. New York: Holt, Rinehart and Winston; 1973.

3. Xiaodong Z. Ting D. Analysis of reading comprehension questions in national matriculation English test from 2017 to 2020 in Zhejiang — Based on PISA 2018 reading assessment framework. Educational Measurement and Evaluation 2020; (12): $14-23$.

4. Chao L. Research on content validity of rational cloze of English National Test Paper in 2019 National Matriculation Entrance Test. Educational Measurement and Evaluation 2020; (3): 33 - 40.

5. Bachman LF, Palmer AS. Language testing in practice. Shanghai: Shanghai Foreign Language Education Press; 1999. 